Article

\title{
Investigation of ZrMnFe/Sepiolite Catalysts on Toluene Degradation in a One-Stage Plasma-Catalysis System
}

\author{
Jianqi Liu ${ }^{1,2}{ }^{\mathbb{D}}, \mathrm{Xin} \mathrm{Liu}^{1}{ }^{1}$, Jiayao Chen ${ }^{3}$, Xianying $\mathrm{Li}^{1}{ }^{1}$, Tianpeng Ma ${ }^{4}$ and Fangchuan Zhong ${ }^{3,5, *}$ \\ 1 College of Environmental Science and Engineering, Donghua University, Shanghai 201620, China; \\ im5156@dhu.edu.cn (J.L.); liuxin0724@126.com (X.L.); seanlee@dhu.edu.cn (X.L.) \\ 2 Institute of Heating, Ventilation and Air Conditioning (IHVAC), Donghua University, Shanghai 201620, China \\ 3 College of Science, Donghua University, Shanghai 201620, China; JiayaoChen1616@163.com \\ 4 School of Electrical \& Information Engineering, North Minzu University, Yinchuan 750021, China; \\ ma_tianpeng@163.com \\ 5 Magnetic Confinement Fusion Research Centre, Ministry of Education, Donghua University, \\ Shanghai 201620, China \\ * Correspondence: fczhong@dhu.edu.cn; Tel.: +86-21-67792518
}

Citation: Liu, J.; Liu, X.; Chen, J.; Li, X.; Ma, T.; Zhong, F. Investigation of $\mathrm{ZrMnFe} /$ Sepiolite Catalysts on

Toluene Degradation in a One-Stage Plasma-Catalysis System. Catalysts 2021, 11, 828. https://doi.org/ $10.3390 /$ catal11070828

Academic Editor: Pedro Modesto Alvarez Pena

Received: 11 June 2021

Accepted: 6 July 2021

Published: 8 July 2021

Publisher's Note: MDPI stays neutral with regard to jurisdictional claims in published maps and institutional affiliations.

Copyright: (c) 2021 by the authors. Licensee MDPI, Basel, Switzerland. This article is an open access article distributed under the terms and conditions of the Creative Commons Attribution (CC BY) license (https:// creativecommons.org/licenses/by/ $4.0 /)$.

\begin{abstract}
Toluene removal by double dielectric barrier charge (DDBD) plasma combined with a ZrM$\mathrm{nFe} /$ Sepiolite (SEP) catalyst was investigated and compared with the results from Fe/SEP, Mn/SEP and MnFe/SEP ones. All the catalysts were prepared by the impregnation method and characterized by XRD, BET, ICP, SEM, TEM, $\mathrm{H}_{2}$-TPR and XPS. The effect of catalysts on toluene degradation efficiency, carbon balance, $\mathrm{CO}_{2}$ selectivity and residual $\mathrm{O}_{3}$ concentration was studied. The experimental results indicated that the $\mathrm{ZrMnFe} / \mathrm{SEP}$ catalyst presented the best catalytic performance. This is because of the high content of lattice oxygen contained in its surface, owing to the addition of $\mathrm{Zr}$. When the SIE was $740 \mathrm{~J} / \mathrm{L}$, the highest toluene removal efficiency $(87 \%)$, carbon balance $(93 \%)$ and $\mathrm{CO}_{2}$ selectivity (51\%) were obtained. The $\mathrm{ZrMnFe} / \mathrm{SEP}$ catalyst had a better ozone inhibition effect than other catalysts. The catalyst has good stability, which the toluene removal efficiency, carbon balance and $\mathrm{CO}_{2}$ selectivity did not decrease significantly after $36 \mathrm{~h}$ of work at a constant energy density. The results indicated that the $\mathrm{ZrMnFe} / \mathrm{SEP}$ catalyst is an efficient catalyst for degradation of toluene by plasma-catalyst measures.
\end{abstract}

Keywords: non-thermal plasma; plasma-catalysis synergy; VOC remediation; air pollution control; toluene; $\mathrm{ZrMnFe}$ /sepiolite

\section{Introduction}

Volatile organic compounds (VOCs) are considered to be one of the main sources of air pollutants. The conventional technologies for VOC removal, such as adsorption, combustion, catalytic oxidation, biological purification, etc., all have their own defects and limitations for practical application [1-4]. Therefore, it is urgent to improve existing treatments or develop new technologies for VOC degradation. In recent years, nonthermal plasma (NTP) has attracted more attention due to its simple structure, non-selective oxidation of VOCs and high removal efficiency at ambient temperature and atmospheric pressure, which is suitable for VOCs treatment. However, studies have shown that the degradation of VOCs by only dielectric barrier discharge (DBD) NTP had the disadvantages of high energy consumption, undesired by-products and low $\mathrm{CO}_{2}$ selectivity, etc. [5-8]. As a solution, the plasma, combined with catalyst measures, has been proved a promising method to solve these problems [7-13].

The raw materials of high-performance catalysts were mostly noble metals, which could not be widely used due to their high cost. As an alternative, transition metal oxides were widely investigated due to their low cost, low toxicity and environmental friendliness [14]. The transitional metal oxides catalysts commonly used for VOC degradation 
are $\mathrm{MnO}_{\mathrm{x}}, \mathrm{CeO}_{\mathrm{x}}, \mathrm{FeO}_{\mathrm{x}}, \mathrm{CuO}, \mathrm{NiO}, \mathrm{TiO}_{2}, \mathrm{ZrO}_{2}$, etc. [15-17]. Among them, $\mathrm{MnO}_{\mathrm{x}}$ has been widely used for synergistic degradation of VOCs combined with NTP, which mainly presented obvious inhibition of ozone [18-20]; $\mathrm{Fe}_{2} \mathrm{O}_{3}$ was a common metal oxide in daily life, which was rarely applied in VOC degradation combined with NTP. The raw material of $\mathrm{Fe}_{2} \mathrm{O}_{3}$ is cheap and environmentally friendly, and it has been proved to be effective in catalytic denitration, wastewater degradation, catalytic combustion degradation of VOCs and in other fields [21-24], which presented good moisture resistance and activity for long-term treatment compared with other catalysts [24]; $\mathrm{ZrO}_{2}$ was often applied in the photocatalytic oxidation of wastewater for abundant oxygen vacancies on its surface. Nanometric $\mathrm{ZrO}_{2}$ has the advantages of a good chemical resistance ionic conductivity and stable photochemical properties, etc. A single catalyst often has some unique advantages, but the overall catalytic performance is still inferior, which needs further improvement.

Catalysts introduced in NTP reactors are usually supported by different porous materials to achieve a higher dispersion of the active components and obtain a better catalytic performance. The most commonly used supports are activated carbon fiber [25], alumina [26], zeolite [27], etc. Exploring and developing the catalyst and the catalysis support with good VOC adsorption surface areas, stable catalytic ability and good anti-deactivation is an important topic of plasma-catalyst VOC decomposition and its practical application $[28,29]$. Sepiolite fiber (SEP) is a fibrous magnesium silicate mineral with the general structure formula of $\mathrm{Si}_{12} \mathrm{Mg}_{8} \mathrm{O}_{30}(\mathrm{OH})_{4}\left(\mathrm{H}_{2} \mathrm{O}\right)_{4} \cdot 8 \mathrm{H}_{2} \mathrm{O}$. It is composed of a silica tetrahedron and magnesium oxide octahedron. It is fibrous and has a unique internal pore structure, with the advantages of good plasticity, a large surface area, and good adsorption behaviors and stability. It has been used to prepare the emerging catalysts due to its low cost, easy availability, and lack of pollution to the environment [30-33]. For example, Ning et al. used sodium-treated sepiolite-supported transition metal catalysts for HCHO oxidation and showed that elevated acidity, the abundance of oxygen species and low-temperature reducibility were responsible for the excellent catalytic activity of $\mathrm{Cu} / \mathrm{NaSEP}$ [31]. Niu et al. used sepiolite-supported $\mathrm{Cu}_{1-y} \mathrm{Mn}_{2} \mathrm{Ce}_{\mathrm{y}} \mathrm{O}_{\mathrm{x}}$ in the oxidation reaction of toluene, the results showed that sepiolite provides a large number of physical adsorption sites for gas-solid phase reactions and $20 \%$ of $\mathrm{Cu}_{0.8} \mathrm{Mn}_{2} \mathrm{Ce}_{0.2} \mathrm{O}_{x}$ / sepiolite is able to remove toluene completely at a temperature of $289^{\circ} \mathrm{C}$ [32]. Htet used sepiolite-supported $\mathrm{BiVO}_{4}$ nanocomposites for efficient photocatalytic degradation of organic pollutants and the results showed that the combination of sepiolite clay could suppress the photogenerated electron-hole pairs recombination and significantly improved the photoelectrochemical activity of monoclinic $\mathrm{BiVO}_{4} /$ sepiolite nanocomposites [33]. Up to now, the study of VOC decomposition by NTP combining with sepiolite-supported catalysts is rarely reported.

In this paper, a cylindrical double dielectric barrier discharge (DDBD) reactor, as one of the main atmosphere plasma generators, was used to investigate toluene degradation by NTP combined with catalysts [13,34-36]. Sepiolite fiber was used as the catalyst carrier, and $\mathrm{Fe}_{2} \mathrm{O}_{3}, \mathrm{MnO}_{2}$ and $\mathrm{ZrO}_{2}$ were compounded to prepare a new $\mathrm{ZrMnFeO}_{\mathrm{x}}$ catalyst, so that the catalyst can simultaneously present the advantages of different single catalysts. VOC degradation by NTP, combined with different catalysts, was carried out. The toluene degradation rate, ozone production and carbon oxide production were compared and analyzed.

\section{Results and Discussion}

\subsection{The Effect of Catalysis}

Toluene removal efficiency, carbon balance, $\mathrm{CO}_{2}$ selectivity and ozone production of toluene degradation in different systems are presented in Figure 1. As shown in Figure 1a, the toluene removal efficiency in different systems kept increasing with the rising of SIE, which was the same as the results in published literature $[35,37,38]$. The increase in SIE could lead to the generation of more high-energy electrons and active species, which were beneficial for the oxidation of VOCs molecules. Toluene removal efficiency in a SEP+NTP system was promoted to a certain extent compared with that in an NTP system, which was mainly due to the increase in micro-discharge in the discharge area. With the 
introduction of catalysts, toluene removal efficiency was further enhanced. For example, toluene removal efficiency was $65 \%$ in a SEP+NTP system, while values of $69 \%$ and $78 \%$ were found in a Mn/SEP+NTP system and Fe/SEP+NTP system, respectively, with an SIE of $740 \mathrm{~J} / \mathrm{L}$. When Mn was doped into the Fe/SEP catalyst, in a MnFe/SEP+NTP system, a slight enhancement of $3.8 \%$ was achieved compared with that in a Fe/SEP+NTP system. When further doped with $\mathrm{Zr}$, a toluene removal efficiency of $87 \%$ was finally obtained in the $\mathrm{ZrMnFe} / \mathrm{SEP}+\mathrm{NTP}$ system, which led to the highest enhancement of $11.5 \%$ compared with that in Fe/SEP+NTP system.

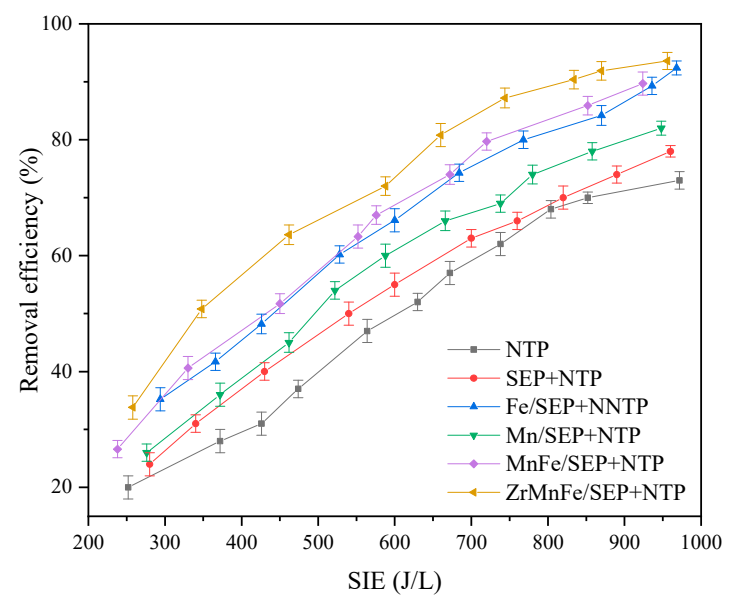

(a)

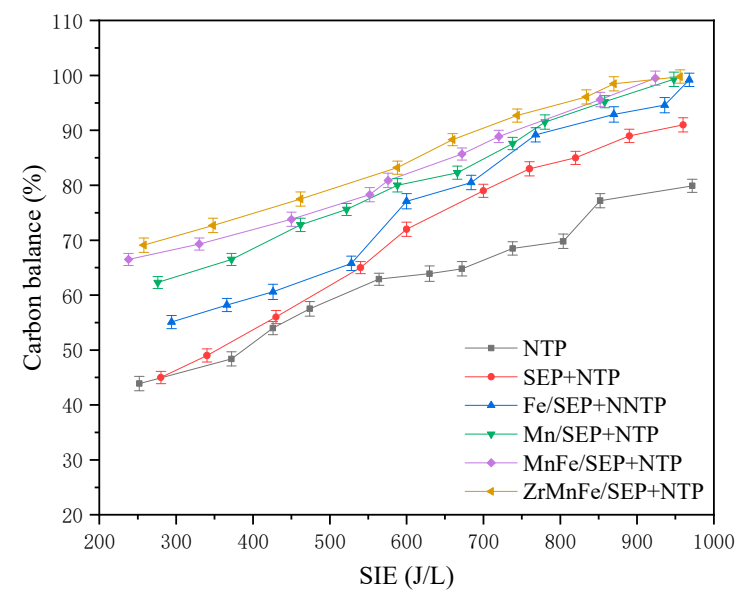

(c)

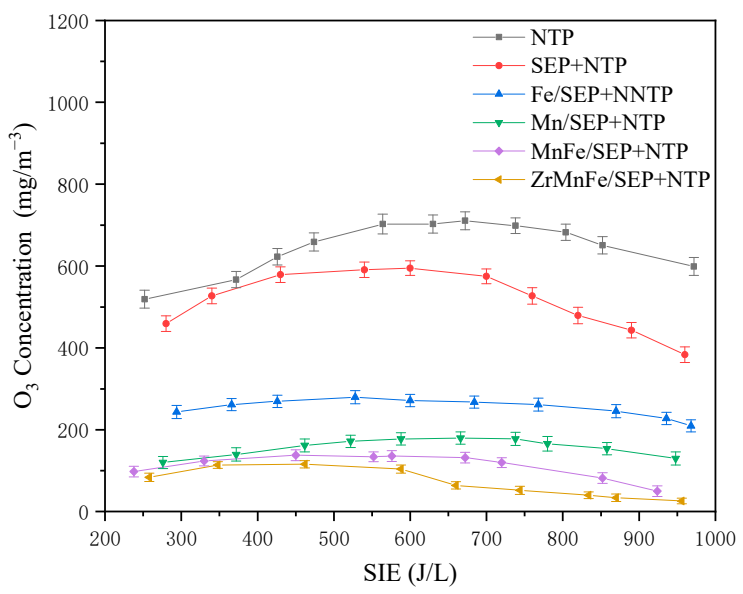

(b)

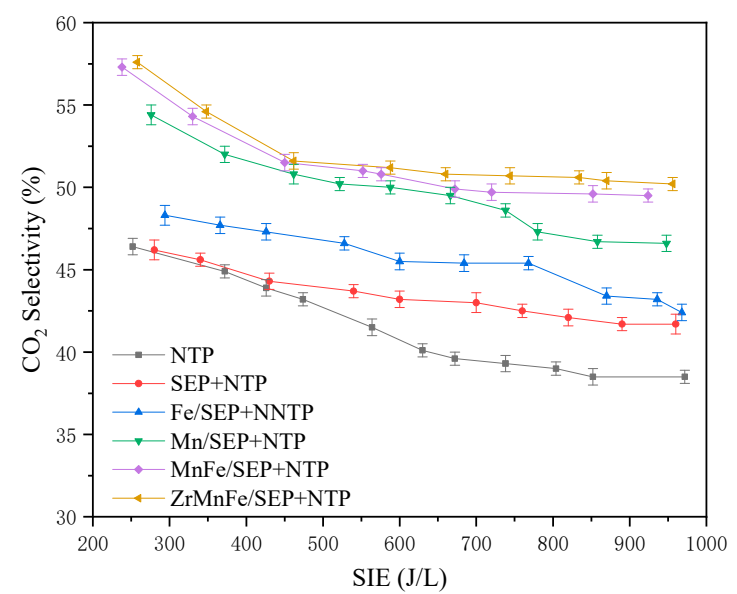

(d)

Figure 1. Effect of catalyst position on toluene removal $\left(\mathrm{RH}=6 \%\right.$ and $\left.\mathrm{T}=20 \pm 2{ }^{\circ} \mathrm{C}\right)$ : (a) removal efficiency; (b) ozone concentration; (c) carbon balance; (d) $\mathrm{CO}_{2}$ selectivity.

Ozone was an inevitable by-product in the process of VOC degradation by NTP, which could cause damage to the environment and the human body. As presented in Figure 1b, the ozone production increased first and then decreased with the increase in SIE. The formation of ozone could be described as follows [39]:

$$
\begin{gathered}
\mathrm{e}+\mathrm{O}_{2} \rightarrow 2 \mathrm{O}+e \\
\mathrm{O}+\mathrm{O}_{2}+\mathrm{M} \rightarrow \mathrm{O}_{3}+\mathrm{M}
\end{gathered}
$$

As the rising of SIE, more high-energy electrons were generated, and more oxygen atoms were generated by the collision of oxygen molecules with high-energy electrons, which finally led to the increase in ozone production. However, the temperature in the reactor also increased with the increase in SIE due to the ohmic effect, which could lead to 
the decomposition of ozone [12]. On the other hand, the ozone production was obviously inhibited with the introduction of catalysts [37,38]. For instance, the ozone concentration was $272 \mathrm{ppm}$ in a SEP+NTP system, while the value was $132 \mathrm{ppm}$ in a Fe/SEP+NTP system with a SIE of $740 \mathrm{~J} / \mathrm{L}$. Compared with the Fe/SEP+NTP system, a more obvious inhibitory effect on ozone production was observed in the Mn/SEP+NTP system, where a lower ozone concentration of $90 \mathrm{ppm}$ was measured at the outlet of the reactor. The lowest ozone production at the same SIE was obtained in the $\mathrm{ZrMnFe} / \mathrm{SEP}+\mathrm{NTP}$ system, where the ozone concentration was only $27 \mathrm{ppm}$.

Carbon balance and $\mathrm{CO}_{2}$ selectivity were frequently applied to characterize the mineralization of VOC degradation. As shown in Figure 1c, d, the carbon balance of toluene degradation in different systems increased with the increase in SIE, while the $\mathrm{CO}_{2}$ selectivity decreased. Both carbon balance and $\mathrm{CO}_{2}$ selectivity were significantly improved with the introduction of catalysts. For example, when the SIE was $740 \mathrm{~J} / \mathrm{L}$, the carbon balance in the NTP system was $68 \%$, while the value was $86 \%$ in the Fe/SEP+NTP system, which led to an increase of $20.6 \%$. The $\mathrm{CO}_{2}$ selectivity, meanwhile, was $39.1 \%$ in the NTP system but $45.4 \%$ in the Fe/SEP+NTP system. When Mn was doped with the Fe/SEP catalyst, the mineralization was further improved, and the carbon balance and $\mathrm{CO}_{2}$ selectivity were $90 \%$ and $49.5 \%$, respectively, in the MnFe/SEP+NTP system. When further doped with $\mathrm{Zr}$, the highest carbon balance and $\mathrm{CO}_{2}$ selectivity of $93 \%$ and $50.7 \%$ were obtained in the $\mathrm{ZrMnFe} / \mathrm{SEP}+\mathrm{NTP}$ system. The introduction of catalysts increased the micro-discharge in the discharge area, which led to the increase in active species that are beneficial (such as $\mathrm{O} \cdot$ and $\mathrm{OH}$ ) to the further oxidation of intermediate products of toluene degradation [39]. The decomposition of ozone on the surface of the catalyst could also be responsible for the improvement of mineralization. The oxygen atom produced by ozone decomposition had a strong oxidizability, which could further oxidize the intermediate products.

\subsection{Durability of Catalyst}

Figure 2 shows the $36 \mathrm{~h}$ data of toluene treated with $\mathrm{ZrMnFe} / \mathrm{SEP}$ when the SIE is $740 \mathrm{~J} / \mathrm{L}$ and $\mathrm{RH}$ is $5 \%$. As shown, the removal efficiency of toluene is stable at $87 \%$, the $\mathrm{CO}_{2}$ selectivity is stable at $50.7 \%$, the carbon balance is stable at $92.6 \%$ and the ozone concentration is stable at about $27 \mathrm{ppm}$. The catalyst performance was not significantly reduced after $36 \mathrm{~h}$ of continuous use. Therefore, the $\mathrm{ZrMnFe} / \mathrm{SEP}$ catalyst has high catalytic stability when applied for degradation of toluene.

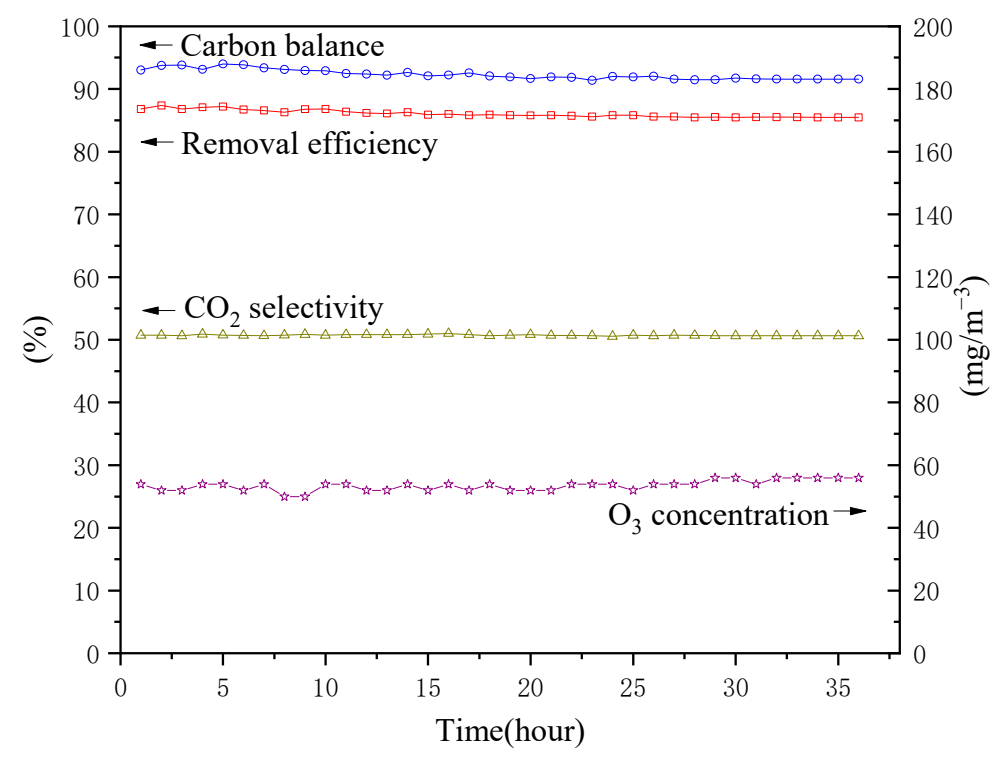

Figure 2. The catalytic stability of $\mathrm{ZrMnFe} / \mathrm{SEP}$ on the toluene removal over $36 \mathrm{~h}(\mathrm{RH}=6 \%$ and $\mathrm{SIE}=750 \mathrm{~J} / \mathrm{L}$ ). 


\section{Materials and Methods}

\subsection{Experimental Setup}

The experimental setup is shown in Figure 3. The compressed air from an air compressor was dried by an air purification unit (75-52NA, Parker Hannifin Co., Cleveland, OH, USA). One path of the dried air was passed into a bubbling tank containing pure toluene liquid (A.R., Sinopharm Chemical Reagent Co., Ltd., Shanghai, China) to obtain a high concentration of toluene gas. The high-concentration toluene gas was stored in a buffer tank $(60 \mathrm{~L})$ to stabilize the concentration. The high-concentration toluene gas output from the buffer tank was further diluted by another path of air from an air compressor before treatment. Two mass flow controllers (MFCs) (D07, Beijing Sevenstar Electronics Co., Ltd., Beijing, China) were used to control the flow rate of high-concentration toluene gas and air to obtain the required concentration of toluene for experiments. In the experiments, the total gas flow rate was fixed at $1 \mathrm{~L} / \mathrm{min}$, the initial toluene concentration was $300 \pm 10 \mathrm{ppm}$, the gas temperature (T) was $20 \pm 2{ }^{\circ} \mathrm{C}$ and relative humidity (RH) was $5 \%$. Then, $2 \mathrm{~g}$ of catalyst that had both ends fixed with glass fiber was set inside the plasma area, and the volumetric space velocity (GHSV) was $15,000 \mathrm{~h}^{-1}$.

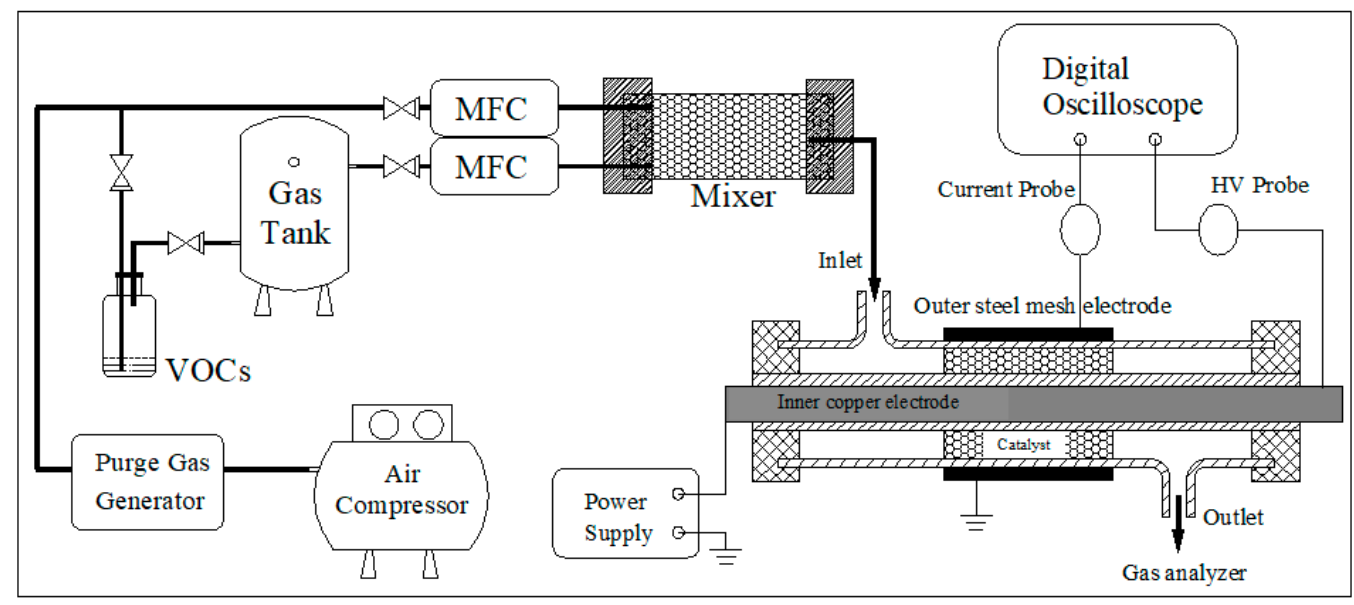

Figure 3. Schematic of plasma catalysis for toluene removal.

The DDBD reactor used in the experiment was made up of two coaxial quartz tubes. The outer diameters of the outer and inner tubes were 20 and $8 \mathrm{~mm}$, respectively, and the thicknesses were 1.5 and $1 \mathrm{~mm}$, respectively. A copper rod with a diameter of $6 \mathrm{~mm}$ was placed inside the inner tube and served as the high-voltage electrode. The dense wire mesh wound around the outer tube's wall served as the ground electrode. The length of the wire mesh covering the outer tube was $100 \mathrm{~mm}$. A high-voltage pulse modulation power supply (CTP-2000 k/P, Nanjing Suman Electronics Co., Ltd., Nanjing, China) was used for discharge. In the experiment, the pulse repetition frequency and duty cycle of the power supply were fixed at $150 \mathrm{~Hz}$ and $20 \%$, respectively, which, as has been proved, could improve the VOC degradation energy yield greatly in the DBD reactor.

\subsection{Catalyst Preparation}

(1) Sepiolite purification: The sepiolite fiber used in this experiment was provided by Hebei Yi County Sepiolite Developing Co., LTD (Baoding, China). Put 100 g sepiolite fiber into $500 \mathrm{~mL}$ distilled water and stir for $20 \mathrm{~min}$, let it stand for $60 \mathrm{~min}$, pour out the supernatant, take out the middle layer suspension and filter it with vacuum, put filter cake into a drying oven and dry it at $60{ }^{\circ} \mathrm{C}$ for $24 \mathrm{~h}$.

(2) Sepiolite acid activation: Weigh $90 \mathrm{~g}$ of purified sepiolite, add $450 \mathrm{~mL}$ of $1 \mathrm{~mol} / \mathrm{L}$ hydrochloric acid solution, mechanically stir for $2 \mathrm{~h}$ until no bubbles are generated, pour out the supernatant liquid after standing for $1 \mathrm{~h}$, carry out loop vacuum filtration and wash with water until the filtrate is neutral. The obtained solids were dried at $80^{\circ} \mathrm{C}$ overnight. 
(3) Sepiolite acid modification: Prepare different concentrations of ferric nitrate (A.R., Sinopharm Chemical Reagent Co., Ltd., Shanghai, China), manganous nitrate (A.R., Sinopharm Chemical Reagent Co., Ltd., Shanghai, China), and zirconium nitrate (A.R., Sinopharm Chemical Reagent Co., Ltd., Shanghai, China) solutions as precursors and prepare ZrMnFe/SEP catalysts with different loadings by impregnation. Preparation conditions: Slowly drip different concentrations of precursor solutions onto $10 \mathrm{~g}$ acid-activated sepiolite carrier, solid (sepiolite) liquid (ferric nitrate solution) ratio of 1:1 g/mL, mechanical stirring for $1 \mathrm{~h}$, ultrasound for $0.5 \mathrm{~h}$. Let it stand for $12 \mathrm{~h}$, dry it at $80{ }^{\circ} \mathrm{C}$ for $24 \mathrm{~h}$, and calcined at $450{ }^{\circ} \mathrm{C}$ for $4 \mathrm{~h}$ in air.

Fe element content was $5 \mathrm{wt} \%$ in the Fe/SEP, MnFe/SEP and ZrMnFe/SEP catalysts, Mn element content was $5 \mathrm{wt} \%$ in the MnFe/SEP and ZrMnFe/SEP catalysts, Zr element content was $2 \mathrm{wt} \%$ in the $\mathrm{ZrMnFe} / \mathrm{SEP}$ catalysts.

\subsection{Catalyst Characterization}

The model of Brunauer-Emmett-Teller (BET) was used to calculate the specific surface areas and the Barrett-Joyner-Halenda (BJH) model was used to analyze the pore size distributions based on the $\mathrm{N}_{2}$ adsorption-desorption isotherms recorded by an automatic specific surface and micropore pore size analyzer (ASAP2020M, Micromeritics Instruments Co., Norcross, GA, USA). All samples were vacuum degassed at $300{ }^{\circ} \mathrm{C}$ for $3 \mathrm{~h}$ before the measurement. The morphology and composition of catalyst particles were investigated by a field emission scanning electron microscope (FE-SEM, S-4800, Hitachi Ltd., Tokyo, Japan) operating at $5 \mathrm{kV}$. The sizes and lattices of samples were studied by a high-resolution transmission electron microscope (HRTEM, JEM-2100F, JEOL Ltd., Tokyo, Japan) operated at $100 \mathrm{kV}$ accelerating voltage. TEM lattice resolution: $\leq 0.10 \mathrm{~nm}$. The phase and crystallinity of the sample was performed in an X-ray diffractometer (XRD, D/Max-2550PC, Rigaku Service Co., Ltd., Tokyo, Japan) using $\mathrm{Cu} \mathrm{K} \alpha\left(1.5406 \AA\right.$ ) radiation, in the $5-90^{\circ} 2 \theta$ range, with a scanning velocity of $2^{\circ} / \mathrm{min}$. Temperature-programmed reduction of $\mathrm{H}_{2}\left(\mathrm{H}_{2}-\mathrm{TPR}\right)$ was performed on a chemisorption analyzer (Autochem 2920-Hiden HPR20, Micrometric, Norcross, GA, USA). All samples were pretreated with $\mathrm{N}_{2}$ at $300{ }^{\circ} \mathrm{C}$ for 30 min before the measurement. X-ray photoelectron spectroscopy (XPS, EscaLab 250Xi, Thermo Fisher Scientific, Waltham, MA, USA) was employed to determine the Fe 2p, Mn 2p, Zr 3d and $\mathrm{O} 1 \mathrm{~s}$ binding energies of surface species of the sample; the data were calibrated against the $\mathrm{C}$ 1s peak of contaminant carbon at $284.8 \mathrm{eV}$. The amounts of $\mathrm{Zr}$, Mn and Fe elements in catalysts were examined by inductively coupled plasma optical emission spectroscopy (ICP-OES) measurements.

\subsection{Evaluation Method}

The discharge voltage $(V)$ and current $(I)$ were measured by a high-voltage probe (P6015A, Tektronix, Beaverton, OR, USA) and a current probe (ETA5315, Suzhou Zongye Electronics Co., Ltd., Suzhou, China), respectively, and recorded by a digital oscilloscope (MDO3032, Tektronix, OR, USA).

The calculation of discharge power $(P)$ can be calculated by Equation (3).

$$
P=f \int_{0}^{T} V(t) I(t) d t
$$

where $T$ is the pulse duration, $s ; f$ is the modulated pulse frequency, $\mathrm{Hz}$.

Then, the specific input energy $(S I E)$, which was often used to characterize the discharge, can be calculated by Equation (4).

$$
\operatorname{SIE}(\mathrm{J} / \mathrm{L})=\frac{P}{F} \times 60
$$

where $P$ is the discharge power of the DDBD reactor, $W ; F$ is the total flow rate of the mixed gas entering the reactor, $\mathrm{L} / \mathrm{min}$. 
Toluene conversion (RE) can be calculated by Equation (5).

$$
R E(\%)=\frac{C_{i n}-C_{o u t}}{C_{\text {in }}} \times 100 \%
$$

where $C_{\text {in }}$ and $C_{\text {out }}$ are the initial concentrations of toluene before and after degradation, ppm.

The concentrations of toluene, $\mathrm{CO}$ and $\mathrm{CO}_{2}$ before and after degradation were determined by gas chromatography (GC2060III, Shanghai Ruimin Instrument Co., Ltd., China) with a FID detector and a methanation conversion furnace.

The carbon balance $(C B)$ was calculated by Equation (6).

$$
C B(\%)=\frac{n_{\mathrm{CO}}+n_{\mathrm{CO}_{2}}}{7 \times n_{\mathrm{C}_{7} \mathrm{H}_{8}}} \times 100 \%
$$

where $n_{\mathrm{C}_{7} \mathrm{H}_{8}}$ is the concentration of removed toluene, $\mathrm{ppm} ; n_{\mathrm{CO}_{2}}$ and $n_{\mathrm{CO}}$ are the concentrations of $\mathrm{CO}_{2}$ and $\mathrm{CO}$ generated after reaction, respectively, ppm.

The $\mathrm{CO}_{2}$ selectivity $\left(\mathrm{S}_{\mathrm{CO}_{2}}\right)$ can be calculated by Equation (7).

$$
S_{\mathrm{CO}_{2}}(\%)=\frac{n_{\mathrm{CO}_{2}}}{n_{\mathrm{CO}}+n_{\mathrm{CO}_{2}}} \times 100 \%
$$

An ozone analyzer (GT-2000-k3, Shenzhen Korno Electronics Co., Ltd., Shenzhen, China) was used to measure the ozone concentration at the reactor outlet.

\section{Catalyst Characterization}

\subsection{XRD}

The crystal structures of Fe/SEP, Mn/SEP, MnFe/SEP and ZrMnFe/SEP catalysts were analyzed by XRD. As shown in Figure 4, the XRD pattern of $\mathrm{Fe}_{2} \mathrm{O}_{3}$ (PDF\#89-059), $\mathrm{MnO}_{2}$ (PDF\#24-0735) is presented clearly. The peaks of $\mathrm{Fe}_{2} \mathrm{O}_{3}$ centered at $33.1^{\circ}$ and $35.6^{\circ}$ could be assigned to (104) and (110) planes, and (101) planes of $\mathrm{MnO}_{2}$ could be found at $36.2^{\circ}$. No obvious $\mathrm{ZrO}_{2}$ peak was found, which demonstrated that $\mathrm{ZrO}_{2}$ was evenly dispersed on the surface of the sepiolite carrier. For different catalysts, the sepiolite carrier still maintained its original characteristic structure and part of the peak value decreased.

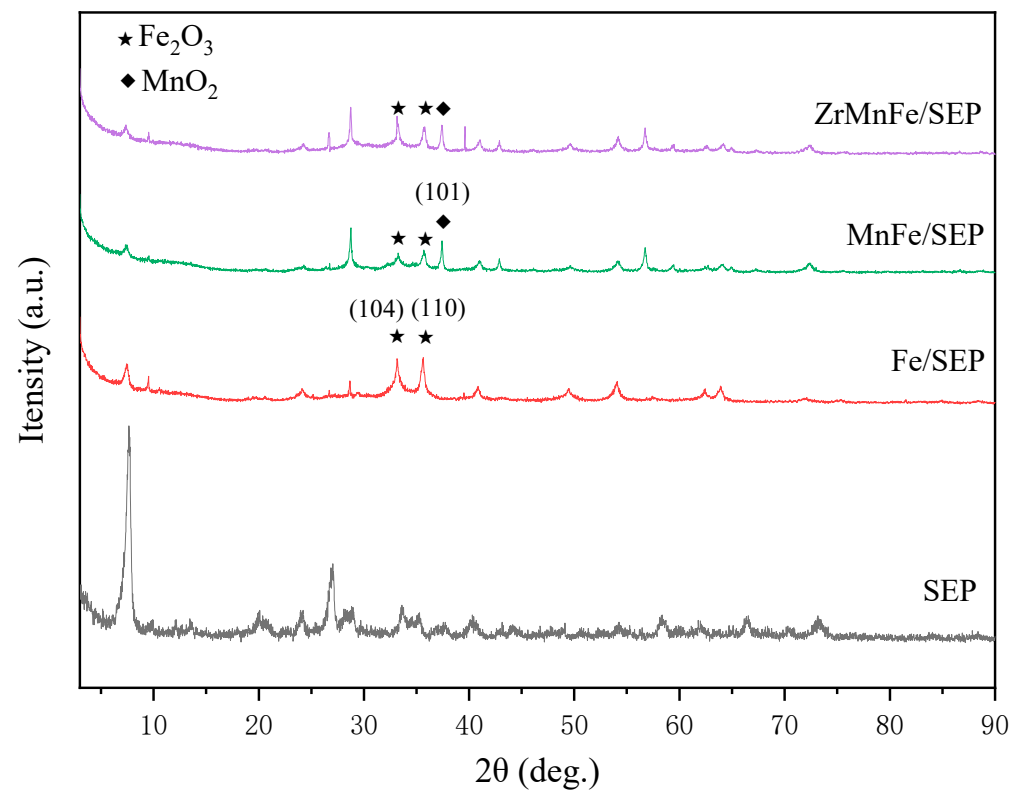

Figure 4. XRD pattern of $\mathrm{ZrMnFe} / \mathrm{SEP}$. 


\subsection{BET}

The surface area, pore diameter and pore volume of catalysts were obtained on the basis of $\mathrm{N}_{2}$ adsorption-desorption isotherms (Table 1). The rank order of surface area for the catalysts was not in agreement with that of catalytic activity, indicating that surface area was not the main factor determining the differences in catalytic activity for these metal-doped catalysts in toluene conversion [40,41].

Table 1. Physical properties of the metal-doped sepiolite catalysts.

\begin{tabular}{|c|c|c|c|c|}
\hline Catalyst Sample & $\begin{array}{l}\text { Surface Area } \\
\left(\mathrm{m}^{2} / \mathrm{g}\right)\end{array}$ & $\begin{array}{l}\text { Pore Volume } \\
\quad\left(\mathrm{cm}^{3} / \mathrm{g}\right)\end{array}$ & $\begin{array}{l}\text { Pore Diameter } \\
(\mathrm{nm})\end{array}$ & $\begin{array}{c}\text { Content }^{(1)} \\
(\mathrm{mg} / \mathrm{g})\end{array}$ \\
\hline SEP & 174.9 & 0.56 & 9.3 & - \\
\hline $\mathrm{Mn} / \mathrm{SEP}$ & 154.8 & 0.53 & 7.2 & Mn: 47.3 \\
\hline $\mathrm{Fe} / \mathrm{SEP}$ & 141.4 & 0.48 & 7.9 & Fe: 46.6 \\
\hline $\mathrm{MnFe} / \mathrm{SEP}$ & 142.1 & 0.49 & 8.9 & $\mathrm{Mn} / \mathrm{Fe}: 47.1 / 46.2$ \\
\hline $\mathrm{ZrMnFe} / \mathrm{SEP}$ & 138.9 & 0.45 & 5.6 & $\mathrm{Zr}: \mathrm{Mn} / \mathrm{Fe}: 17.9 / 46.9 / 46.3$ \\
\hline
\end{tabular}

(1) The analytical result of ICP.

\subsection{SEM and TEM}

The morphology of catalysts was observed by FE-SEM and TEM (Figure 5). It could be seen that sepiolite fiber was covered with many nano metal oxide particles. The sepiolite fiber has a smooth surface and a clear fiber structure (Figure 5a). When iron oxide was loaded on it, small crystal $(10-20 \mathrm{~nm})$ structures formed and some agglomerated together to become cubic iron oxide crystals $(200 \times 200 \mathrm{~nm})$ that could be clearly seen on the surface of the sepiolite fiber (Figure $5 b$ ). After sepiolite fiber was loaded with manganese dioxide, a small spherical $(20-30 \mathrm{~nm})$ crystal structure could be seen, and some small spheres agglomerated together to become flower spherical $(400 \times 400 \mathrm{~nm})$ (Figure $5 \mathrm{c}$ ). The flower spherical manganese dioxide and cubic iron oxide were present on both MnFe/SEP (Figure 5d) and ZrMnFe/SEP (Figure 5e) catalysts. As shown in Figure 5e, the doping of $\mathrm{Zr}$ could inhibit the growth of grain. Lattice fringes with lattice spacing of 0.252 and 0.271 $\mathrm{nm}$ presented in TEM (Figure 5f,g), contributed to the (110) and (104) planes of $\mathrm{Fe}_{2} \mathrm{O}_{3}$ in the $\mathrm{ZrMnFe} / \mathrm{SEP}$ catalyst.

\subsection{XPS}

XPS was used to identify the chemical states of $\mathrm{Fe}, \mathrm{Mn}, \mathrm{Zr}$, and $\mathrm{O}$ on the $\mathrm{ZrMnFe} / \mathrm{SEP}$ catalysts. The elements Fe and O elements were examined by XPS of Fe $2 p$ and $\mathrm{O} 1$ s orbits. The results are illustrated in Figure 6. It can be seen from Figure $6 a$ that Fe $2 \mathrm{p}_{3 / 2}$ and Fe $2 p_{1 / 2}$ have two energy peaks [42,43]. The peaks of $711.4,725.0,709.6 .8$ and $723.3 .6 \mathrm{eV}$ obtained after peak separation were consistent with the standard spectrum of $\mathrm{Fe}_{2} \mathrm{O}_{3}$, which illustrated that the Fe element in the catalyst mainly exists in the form of $\mathrm{Fe}^{3+}$. As shown in Figure 6b, two obvious peaks were presented that located at 640.6 and $641.6 \mathrm{eV}$, which matched with the values reported for $\mathrm{MnO}_{2}$. Two peaks corresponded to $\mathrm{Mn}^{4+}$ and $\mathrm{Mn}^{3+}$ species, respectively. It can be seen from Figure $6 \mathrm{c}$ that the $\mathrm{Zr} 3 \mathrm{~d}_{5 / 2}$ peak at $181.8 \mathrm{eV}$ corresponds to the $\mathrm{Zr}^{4+}$ in $\mathrm{ZrO}_{2}$ [42].

The XPS spectra and Gaussian line that fitted O 1s spectra of ZrMnFe/SEP are shown in Figure 6d. The binding energy at around $530.8 \mathrm{eV}$ could be attributed to the lattice oxygen, and the binding energy at around $531.9 \mathrm{eV}$ could be related to the adsorbed oxygen. The proportion of lattice oxygen of $\mathrm{ZrMnFe} / \mathrm{SEP}$ was higher than that of MnFe/SEP, $\mathrm{Mn} / \mathrm{SEP}$ and $\mathrm{Fe} / \mathrm{SEP}$. It is indicated that $\mathrm{Zr}$ could increase the content of lattice oxygen. A high lattice oxygen content was conducive to the catalytic oxidation of organic compounds. 

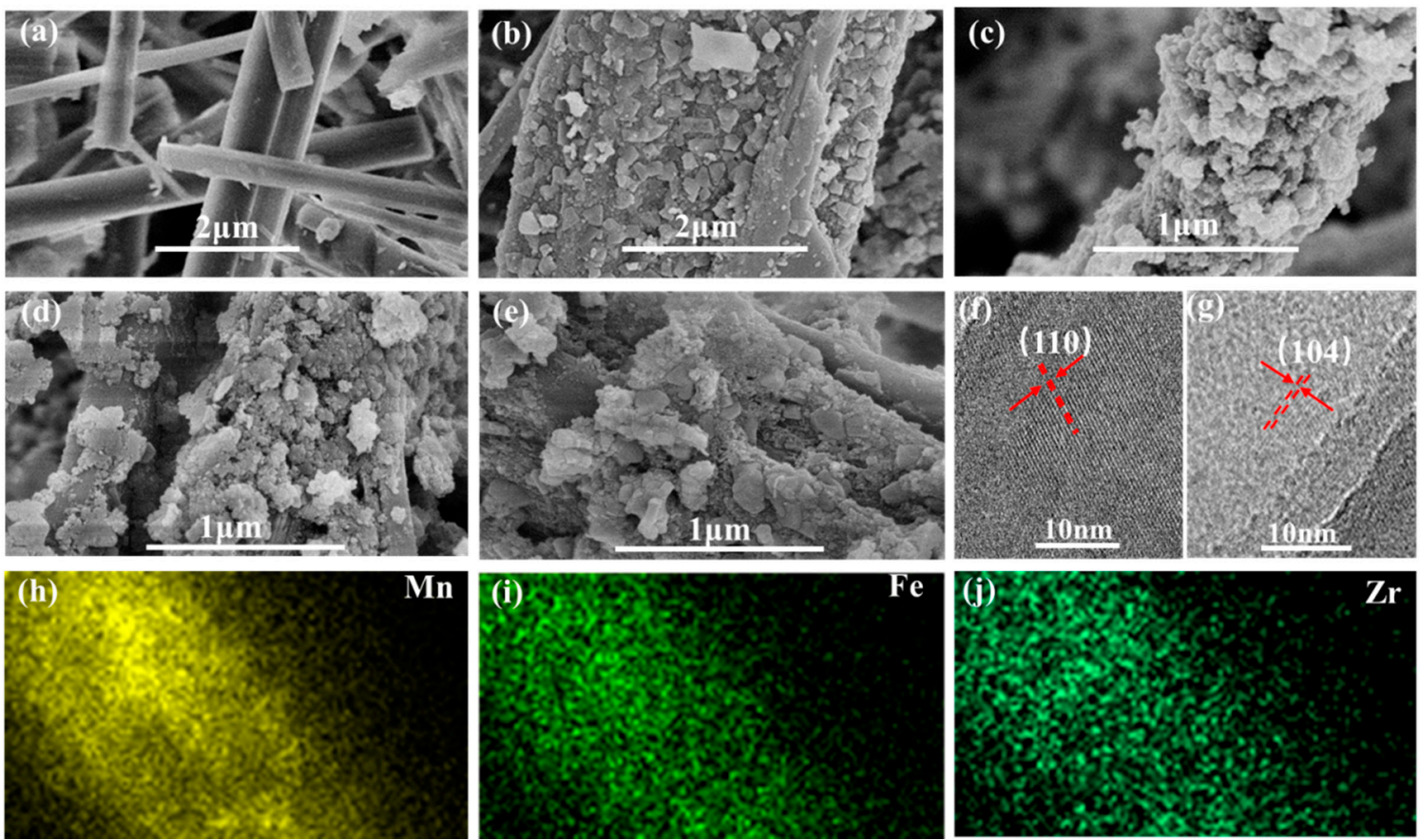

Figure 5. SEM and TEM of ZrMnFe/SEP: (a) SEM of SEP, (b) SEM of Fe/SEP, (c) SEM of Mn/SEP, (d) SEM of MnFe/SEP, (e) SEM of ZrMnFe/SEP, (f,g) Fe (110) planes and Fe (104) planes in TEM of ZrMnFe/SEP, (h-j) mapping images of $\mathrm{ZrMnFe} / \mathrm{SEP}$.

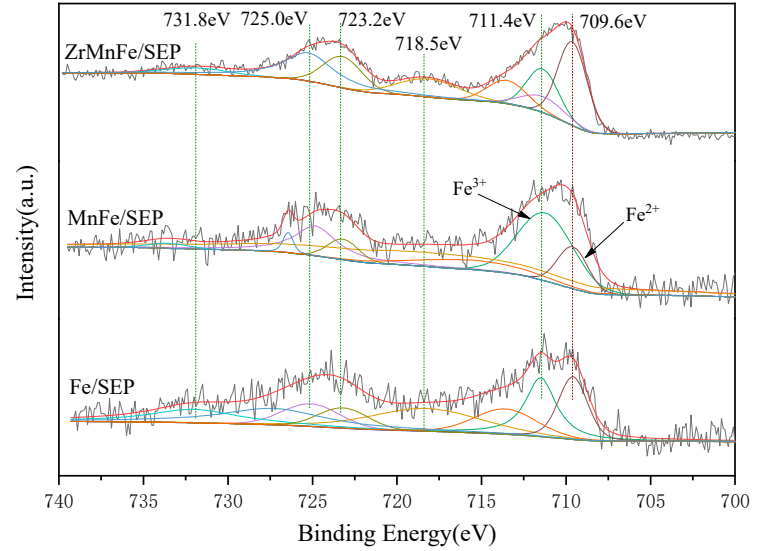

(a)

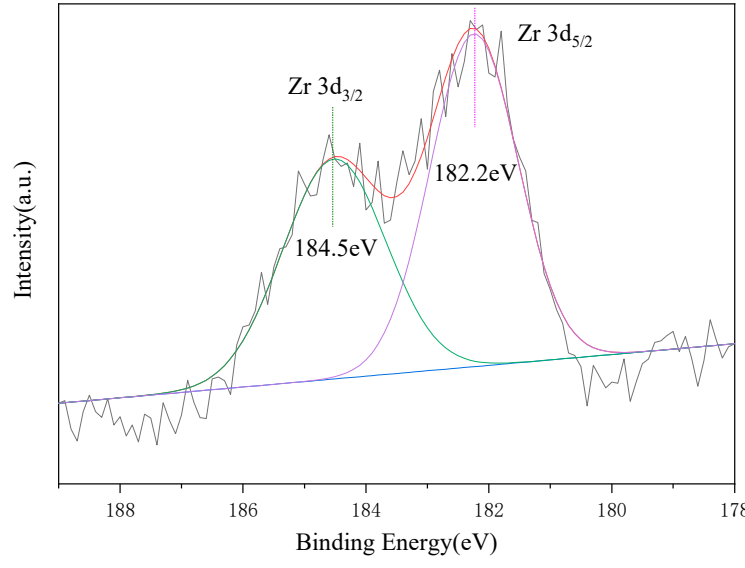

(c)

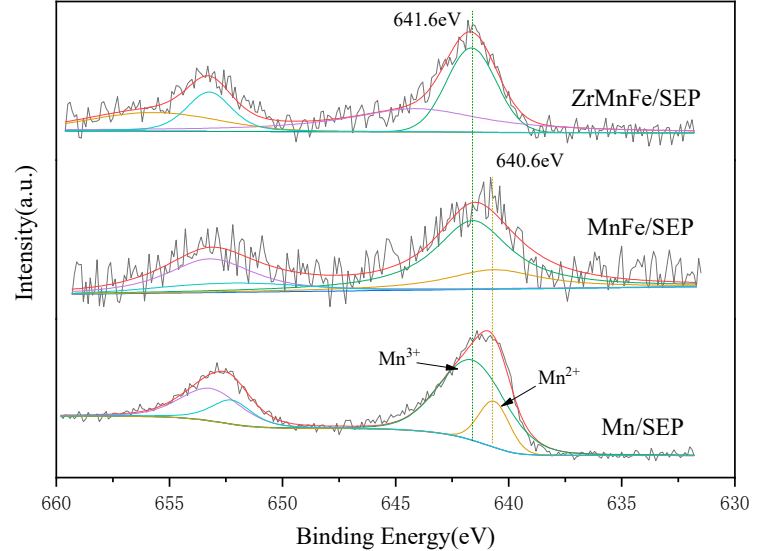

(b)

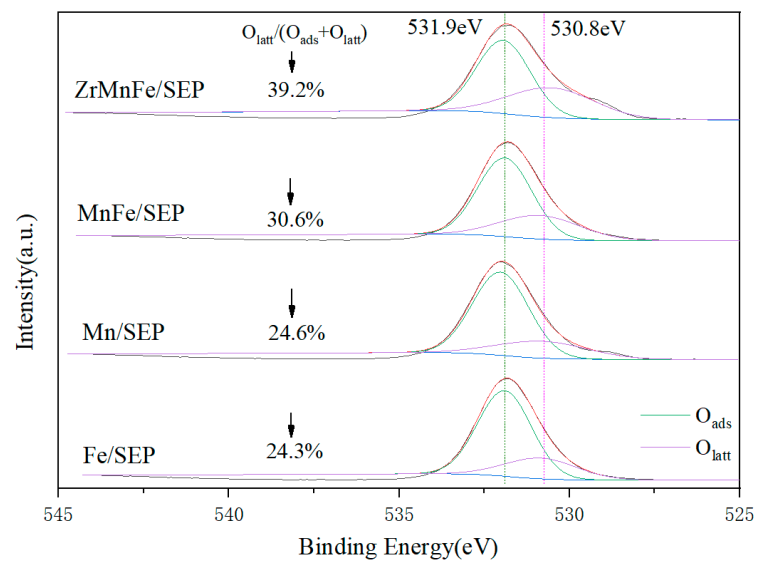

(d)

Figure 6. XPS pattern of ZrMnFe/SEP: (a) Fe 2p XPS spectra, (b) Mn 2p XPS spectra, (c) Zr 3d XPS spectra, (d) O 1s XPS spectra. 


\section{Conclusions}

The $\mathrm{ZrMnFe} / \mathrm{SEP}$ catalysts were prepared by the impregnation method and the enhancement of toluene removal by DDBD in the plasma-catalysis configuration was investigated. In the experiment, sepiolite fiber had a larger specific surface area and good stability. The toluene conversion rate, carbon balance and carbon dioxide selectivity were greatly improved, while the generation of ozone was suppressed with the addition of $\mathrm{ZrO}_{2}$, $\mathrm{MnO}_{2}$ and $\mathrm{Fe}_{2} \mathrm{O}_{3}$. The reduction in temperature of composite metal ( $\mathrm{Zr}, \mathrm{Mn}$ and $\mathrm{Fe}$ ) oxide was lower and this was helpful to improve the catalytic performance. ZrMnFe/SEP+NTP could increase toluene removal rate by $40 \%$ compared to only NTP, and the ozone concentration was reduced from 350 to $27 \mathrm{ppm}$. The results showed that $\mathrm{ZrMnFe} / \mathrm{SEP}$ is an efficient and stable catalyst for plasma-catalyst degradation of toluene.

Author Contributions: J.L., X.L. (Xin Liu) and J.C.: experiments, data treatment and formal analysis; X.L. (Xianying Li): review and editing; T.M.: methodology and funding acquisition; J.L. and F.Z.: data treatment and formal analysis, conceptualization, methodology, validation, writing, review and editing, project administration and funding acquisition. All authors have read and agreed to the published version of the manuscript.

Funding: This research was funded by Fundamental Research Funds for the Central Universities, grant numbers 2232020G-10 and 2232017D-25; this research was also supported by the Natural Science Foundation of Ningxia Hui Autonomous Region, grant number 2020AAC03241.

Acknowledgments: The authors are thankful for the funding from Donghua University and the Natural Science Foundation of the Ningxia Hui Autonomous Region.

Conflicts of Interest: The authors declare no conflict of interest.

\section{References}

1. Du, C.; Lu, S.; Wang, Q.; Buekens, A.G.; Ni, M.; Debecker, D.P. A review on catalytic oxidation of chloroaromatics from flue gas. Chem. Eng. J. 2018, 334, 519-544. [CrossRef]

2. Dan, H.E.; LIU, L.S.; Jun, R.E.N.; HU, T.P. Catalytic combustion of volatile organic compounds over $\mathrm{CuO}^{-C e O} \mathrm{C}_{2}$ supported on $\mathrm{SiO}_{2}-\mathrm{Al}_{2} \mathrm{O}_{3}$ modified glass-fiber honeycomb. J. Fuel Chem. Technol. 2017, 45, 356-361.

3. Kamal, M.S.; Razzak, S.A.; Hossain, M.M. Catalytic oxidation of volatile organic compounds (VOCs) -A review. Atmos. Environ. 2016, 140, 117-134. [CrossRef]

4. Dobslaw, D.; Schller, J.; Krivak, D.; Helbich, S.; Engesser, K.H. Performance of different biological waste air purification processes in treatment of a waste gas mix containing tert-butyl alcohol and acetone: A comparative study. Chem. Eng. J. 2019, 355, 572-585. [CrossRef]

5. Zhang, X.; Gao, B.; Creamer, A.E.; Cao, C.; Li, Y. Adsorption of VOCs onto engineered carbon materials: A review. J. Hazard. Mater. 2017, 338, 102-123. [CrossRef]

6. Kim, H.H.; Prieto, G.; Takashima, K.; Katsura, S.; Mizuno, A. Performance evaluation of discharge plasma process for gaseous pollutant removal. J. Electrost. 2002, 55, 25-41. [CrossRef]

7. Ma, T.; Jiang, H.; Liu, J.; Zhong, F. Decomposition of benzene using a pulse-modulated DBD plasma. Plasma Chem. Plasma Process. 2016, 36, 1533-1543. [CrossRef]

8. Yao, X.; Zhang, J.; Liang, X.; Long, C. Plasma-catalytic removal of toluene over the supported manganese oxides in DBD reactor: Effect of the structure of zeolites support. Chemosphere 2018, 208, 922-930. [CrossRef] [PubMed]

9. Liu, R.; Song, H.; Li, B.; Li, X.; Zhu, T. Simultaneous removal of toluene and styrene by non-thermal plasma-catalysis: Effect of VOCs interaction and system configuration. Chemosphere 2020, 263, 127893. [CrossRef]

10. Wang, L.; Zhang, C.; He, H.; Liu, F.; Wang, C. Effect of doping metals on OMS-2 $/ \gamma-\mathrm{Al}_{2} \mathrm{O}_{3}$ catalysts for plasma-catalytic removal of o-Xylene. J. Phys. Chem. C 2016, 120, 6136-6144. [CrossRef]

11. Jiang, N.; Qiu, C.; Guo, L.; Shang, K.; Lu, N.; Li, J.; Wu, Y. Post plasma-catalysis of low concentration VOC over alumina-supported silver catalysts in a surface/packed-bed hybrid discharge reactor. Water Air Soil Pollut. 2017, 228, 113.1-113.11. [CrossRef]

12. He, C.; Yu, Y.; Yue, L.; Qiao, N.; Li, J.; Shen, Q.; Yu, W.; Chen, J.; Hao, Z. Low-temperature removal of toluene and propanal over highly active mesoporous $\mathrm{CuCeOx}$ catalysts synthesized via a simple self-precipitation protocol. Appl. Catal. B Environ. 2014, 147, 156-166. [CrossRef]

13. Li, J.; Zhang, H.; Ying, D.; Wang, Y.; Sun, T.; Jia, J. In plasma catalytic oxidation of toluene using monolith CuO foam as a catalyst in a wedged high voltage electrode dielectric barrier discharge reactor: Influence of reaction parameters and byproduct control. Int. J. Environ. Res. Public Health 2019, 16, 711. [CrossRef]

14. Chung, W.C.; Mei, D.H.; Tu, X.; Chang, M.B. Removal of VOCs from gas streams via plasma and catalysis. Catal. Rev. 2019, 61, 270-331. [CrossRef] 
15. Wu, J.; Huang, Y.; Xia, Q.; Zhong, L. Decomposition of toluene in a plasma catalysis system with $\mathrm{NiO}_{2} \mathrm{MnO}_{2}, \mathrm{CeO}_{2}, \mathrm{Fe}_{2} \mathrm{O}_{3}$, and CuO catalysts. Plasma Chem. Plasma Process. 2013, 33, 1073-1082. [CrossRef]

16. Wang, W.; Wang, H.; Zhu, T.; Fan, X. Removal of gas phase low-concentration toluene over Mn, Ag and Ce modified HZSM-5 catalysts by periodical operation of adsorption and non-thermal plasma regeneration. J. Hazard. Mater. 2015, 292, 70-78. [CrossRef]

17. Aouadi, I.; Tatibout, J.M.; Bergaoui, L. $\mathrm{MnOx} / \mathrm{TiO}_{2}$ catalysts for vocs abatement by coupling non-thermal plasma and photocatalysis. Plasma Chem. Plasma Process. 2016, 36, 1485-1499. [CrossRef]

18. Ye, Z.; Jean-Marc, G.; Nathalie, D.G.; Rino, M.; Jean-Fran Ois, L. The design of MnOx based catalyst in post-plasma catalysis configuration for toluene abatement. Catalysts 2018, 8, 91. [CrossRef]

19. Chang, T.; Shen, Z.; Huang, Y.; Lu, J.; Ren, D.; Sun, J.; Cao, J.; LIU, H. Post-plasma-catalytic removal of toluene using $\mathrm{MnO}_{2}-\mathrm{Co}_{3} \mathrm{O}_{4}$ catalysts and their synergistic mechanism. Chem. Eng. J. 2018, 348, 15-25. [CrossRef]

20. Hastuti, E.; Subhan, A.; Amonpattaratkit, P.; Zainuri, M.; Suasmoro, S. The effects of Fe-doping on MnO2: Phase transitions, defect structures and its influence on electrical properties. RSC Adv. 2021, 11, 7808-7823. [CrossRef]

21. Kim, I.H.; Park, C.H.; Woo, T.G.; Jeong, J.H.; Jeon, C.S.; Kim, Y.D. Comparative studies of mesoporous $\mathrm{Fe}_{2} \mathrm{O}_{3} / \mathrm{Al}_{2} \mathrm{O}_{3}$ and $\mathrm{Fe}_{2} \mathrm{O}_{3} / \mathrm{SiO}_{2}$ fabricated by temperature-regulated chemical vapour deposition as catalysts for acetaldehyde oxidation. Catal. Lett. 2018, 148, 454-464. [CrossRef]

22. Su, Y.J.; Jongyoon, B.; Sunyoung, P.; Yong-Ki, P. Plasma-assisted oxidation of toluene over Fe/Zeolite catalyst in DBD reactor using adsorption/desorption system. Catal. Commun. 2018, 113, 36-40.

23. Xia, Y.; Dai, H.; Jiang, H.; Zhang, L.; Deng, J.; Liu, Y. Three-dimensionally ordered and wormhole-like mesoporous iron oxide catalysts highly active for the oxidation of acetone and methanol. J. Hazard. Mater. 2011, 186, 84-91. [CrossRef] [PubMed]

24. Lu, M.; Huang, R.; Wu, J.; Fu, M.; Ye, D. On the performance and mechanisms of toluene removal by FeOx/sba-15-assisted non-thermal plasma at atmospheric pressure and room temperature. Catal. Today 2015, 242, 274-286. [CrossRef]

25. Wang, Y.; Jiang, S.; Liu, F.; Zhao, C.; Zhao, D.; Li, X. Study on preparation and toluene removal of BiOI/Bi2WO6/ACF photocatalyst. Appl. Surf. Sci. 2019, 488, 161-169. [CrossRef]

26. Lu, H.; Yao, X.; Li, J.; Yao, S.; Nozaki, T. Mechanism on the plasma-catalytic oxidation of graphitic carbon over $\mathrm{Au} / \gamma-\mathrm{Al}_{2} \mathrm{O}_{3}$ by in situ plasma drifts-mass spectrometer. J. Hazard. Mater. 2020, 396, 122730. [CrossRef] [PubMed]

27. Veerapandian, S.K.P.; De Geyter, N.; Giraudon, J.M.; Lamonier, J.F.; Morent, R. The use of zeolites for VOCs abatement by combining non-thermal plasma, adsorption, and/or catalysis: A review. Catalysts 2019, 9, 98. [CrossRef]

28. Vandenbroucke, A.M.; Morent, R.; De Geyter, N.; Leys, C. Non-thermal plasmas for non-catalytic and catalytic VOC abatement. J. Hazard. Mater. 2011, 195, 30-54. [CrossRef]

29. Feng, X.; Liu, H.; He, C.; Shen, Z.; Wang, T. Synergistic effect and mechanism of non-thermal plasma catalysis system in volatile organic compounds removal: A review. Catal. Sci. Technol. 2018, 8, 936-954. [CrossRef]

30. Azadeh, G.; Bahram, B.; Abbas, S.; Leila, M. Molybdenum complex supported on amine-functionalized natural sepiolite-type mineral as a recyclable inorganic-organic hybrid catalyst for epoxidation of alkenes. Mater. Chem. Phys. 2018, 218, 326-335.

31. Dong, N.; Ye, Q.; Chen, M.; Cheng, S.; Dai, H. Sodium-treated sepiolite-supported transition metal (Cu, Fe, Ni, Mn, or Co) catalysts for HCHO oxidation. Chin. J. Catal. 2020, 41, 1734-1744. [CrossRef]

32. Niu, J.; Qian, H.; Liu, J.; Liu, H.; Zhang, P.; Duan, E. Process and mechanism of toluene oxidation using $\mathrm{Cu}_{1-\mathrm{y}} \mathrm{Mn}_{2} \mathrm{Ce}_{\mathrm{y}} \mathrm{O}_{\mathrm{x}} / \mathrm{sepiolite}$ prepared by the co-precipitation method. J. Hazard. Mater. 2018, 357, 332-340. [CrossRef]

33. Hhn, A.; Kai, W.A.; Yuan, L.A.; Akm, C.; Gza, B. Sepiolite supported bivo 4 nanocomposites for efficient photocatalytic degradation of organic pollutants: Insight into the interface effect towards separation of photogenerated charges. Sci. Total Environ. 2020, 722, 137825

34. Zhu, X.; Zhang, S.; Yang, Y.; Zheng, C.; Zhou, J.; Gao, X.; Tu, X. Enhanced performance for plasma-catalytic oxidation of ethyl acetate over La1-xCexCoO3+ $\delta$ catalysts. Appl. Catal. B Environ. 2017, 213, 97-105. [CrossRef]

35. Li, S.J.; Yu, X.; Xiao, Q. Using non-thermal plasma for decomposition of toluene adsorbed on $\gamma$-Al2O3 and ZSM-5: Configuration and optimization of a double dielectric barrier discharge reactor. Chem. Eng. J. 2019, 375, 122027. [CrossRef]

36. Lee, B.; Kim, D.W.; Park, D.W. Decomposition of heptane by dielectric barrier discharge (DBD) plasma reactor having the segmented electrode: Comparison of decomposition mechanisms to toluene. Plasma Chem. Plasma Process. 2020, $40,61-77$. [CrossRef]

37. Guo, Y.F.; Ye, D.Q.; Chen, K.F.; He, J.C. Toluene removal by a DBD-type plasma combined with metal oxides catalysts supported by nickel foam. Catal. Today 2007, 126, 328-337. [CrossRef]

38. Pan, K.L.; Chang, M.B. Plasma catalytic oxidation of toluene over double perovskite-type oxide via packed-bed DBD. Environ. Sci. Pollut. Res. 2019, 26, 12948-12962. [CrossRef] [PubMed]

39. Paulussen, S.; Verheyde, B.; Tu, X.; De Bie, C.; Martens, T.; Petrovic, D.; Bogaerts, A.; Sels, B. Conversion of carbon dioxide to value-added chemicals in atmospheric pressure dielectric barrier discharges. Plasma Sources Sci. Technol. 2010, 19, 34015-34016. [CrossRef]

40. Wang, Y.; He, H.; Zhang, C.; Wang, Y.; Zhang, B. Effects of precursors for manganese-loaded gamma- $\mathrm{Al}_{2} \mathrm{O}_{3}$ catalysts on plasma-catalytic removal of o-xylene. Chem. Eng. J. 2016, 288, 406-413. [CrossRef]

41. Saputra, E.; Muhammad, S.; Sun, H.; Ang, H.M.; Tadé, M.O.; Wang, S. Shape-controlled activation of peroxymonosulfate by single crystal $\alpha-\mathrm{Mn}_{2} \mathrm{O}_{3}$ for catalytic phenol degradation in aqueous solution. Appl. Catal. B Environ. 2014, 154, 246-251. [CrossRef] 
42. Cao, W.; Tan, O.K.; Pan, J.S.; Zhu, W.; Reddy, C.G. Xps characterization of $\mathrm{x} \alpha-\mathrm{Fe}_{2} \mathrm{O}_{3}-(1-\mathrm{x}) \mathrm{ZrO}_{2}$ for oxygen gas sensing application. Mater. Chem. Phys. 2002, 75, 67-70. [CrossRef]

43. Yamashita, T.; Hayes, P. Analysis of XPS spectra of Fe 2+ and Fe 3+ ions in oxide materials. Appl. Surf. Sci. 2008, 254, 2441-2449. [CrossRef] 